\title{
Wikipedia and wikis as forums of information literacy instruction in schools
}

\author{
Eero Sormunen \\ University of Tampere \\ School of Information Sciences \\ eero.sormunen@uta.fi
}

\author{
Heidi Eriksson \\ City of Tampere \\ Upper secondary education \\ heidi.eriksson@tampere.fi
}

\author{
Tuuli Kurkipää \\ City of Tampere \\ Upper secondary education \\ tuuli.kurkipaa@tampere.fi
}

\begin{abstract}
The City of Tampere and the University of Tampere are cooperating on the ongoing "Tieto haltuun" information literacy (IL) project to develop and study new types of IL learning assignments applying social media tools. The overall goal of the study was to learn how writing articles for Wikipedia (a public wiki) and for the school's own wiki can serve as a learning assignment in information literacy instruction.
\end{abstract}

Dhis document has been downloaded from TamPub.uta.fi The Institutional Repository of University of Tampere

In this paper we report how a library visit as one element of the course programme affected students' information behaviour. We wanted to find out how a special IL session in the library can help students to expand the types of sources used. One aim was to investigate how students' tendency to write in their own words instead of copy-pasting and to cite sources appropriately instead of plagiarizing is associated with the type of sources used. Through the case courses we aimed to collect experiences of good practices in IL instruction organized as a collaborative effort on the part of librarians and teachers.

We found that the IL session organized in the local library substantially increased the use of books as sources in writing the articles. The students used sources differently in differently designed assignments. The groups of students writing focused Wikipedia articles used more printed sources, wrote more in their own words and also summarised and synthesised more information from sources than the groups of students writing on more extensive topics for the school's wiki. The lessons learned from the project are discussed both from the teachers' and librarian's perspectives. 


\section{Introduction}

In the school's information literacy (IL) instruction, writing based on sources searched by students themselves is a widely used type of learning assignment. The core of the task is that students search and study multiple texts and compile another text. The goal is that students should read sources thoughtfully, construct knowledge on the given topic, and, drawing on that knowledge and available sources, compile a new text indicating what they have constructed and learned. Through this practical exercise students are expected to learn - in addition to subject content - to search, evaluate and use information effectively and ethically.

In the age of Wikipedia and Google, copy-pasting and plagiarism have become a widely recognized problem that makes it difficult to achieve the intended learning goals of IL assignments. Many students tend to transfer information mechanically from the sources into their own texts instead of transforming it in the cognitive process of knowledge construction (Limberg 1999; McGregor \& Streitenberger 2004; McGregor \& Williamson 2005). In the worst case, the student fails to achieve the learning goals in topical contents as well as in information literacy.

For many librarians and teachers, the use of Google and Wikipedia is inappropriate information behaviour which students should grow out of (see e.g. Achterman 2005; Julien \& Baker 2009). However, others argue that Wikipedia is a useful forum for acquiring good information literacy practices (see e.g. Jennings 2009). We support the view that students' activity in the Web should be seen as an opportunity and that these forums should be used to enhance information literacy instruction.

"Tieto haltuun" ${ }^{1 "}$ is a project that aims to enhance the IL skills of the upper secondary school students in the City of Tampere (age range from 16 to 18). Even though Wikipedia and other wikis are important modern day tools for finding, processing and publishing information, teachers and

\footnotetext{
1 "Tieto haltuun" is a Finnish slogan referring to gaining mastery of both information and knowledge.
} 
students typically do not master their principles well enough to exploit the opportunities they offer. The project librarian therefore took part in these courses teaching the students how to make a proper wiki article and how to seek and process the information for it.

The goal of our study was to find out in detail how students use printed and Web sources in writing their wiki/Wikipedia articles. In the pilot study, two classes - one in biology and one in geography wrote Wikipedia articles. Only a general introduction to information seeking and Wikipedia authoring was included in the programme. In the main study, the students of a literature class wrote Wikipedia articles and the students of a history class wrote wiki articles. This time an organized library visit was included in the course programme to ascertain how this intervention affects students' use of sources.

\section{The "Tieto haltuun" project}

The "Tieto haltuun" project was initiated in 2008 to improve teachers' and students' IL skills in Tampere upper secondary schools. The aim is to integrate IL skills into the school's curriculum. The students are also intended to be able to search for, process and produce information in their future studies in universities and colleges.

The project offers tuition in IL skills both for teachers and students. The information specialist designs the teaching according to the course objectives and topics. Usually the course assignments include portfolios or essays, for which the students have to seek, evaluate and use information independently. The lessons start with an introduction to basic information literacy, such as simple search skills and source criticism. The students are given examples of Web sites, books and other sources as to where and how to find information on the topics of interest. For the rest of the lesson the students search their topics with the help of the information specialist.

In addition to the IL tuition the project endeavours to impart IL skills in the Tampere upper secondary school curriculum in all compulsory subjects. The information specialist takes part in 
maintaining and developing the school libraries. The project has promoted communication between schools and the City Library by organizing meetings and cooperation. For example, two librarians worked for a two-week period in a school library and together with the teaching staff developed new practices for IL.

The role of researchers was to collect and analyse data from the case courses to learn more about students' information behaviour in source-based writing in general, and to give feedback specifically for the further development of information literacy instruction.

\section{Wikis and Wikipedia as forums of IL instruction}

"A wiki is a website whose users can add, modify, or delete its content via a Web browser using a simplified markup language or a rich-text editor. Wikis are typically powered by wiki software and are often created collaboratively, by multiple users." (Wikipedia: http://en.wikipedia.org/wiki/Wiki)

Wikipedia is a participatory encyclopaedia built on a wiki (for the English version visit: http://en.wikipedia.org/wiki/Main_Page). Anybody is invited to contribute by writing and editing articles as one of the Wikipedians. The authoring policy rests on three principles (1) Verifiability, (2) No Original Research and (3) Neutral Point of View (Huvila 2010). Articles should not contain new information or interpretations which have not been published earlier in some reputable forum. The third principle reminds writers to present competing views or balance between them in controversial issues.

Some aspects of Wikipedia make it an authentic and meaningful framework for source-based writing assignments. Overall, students are familiar with the basics of Wikipedia because they search it regularly (Head \& Eisenberg 2010; Harouni 2009). Students seem to trust Wikipedia because their everyday experiences are predominantly positive (Lim 2009) and tend to use it uncritically (Harouni 2009). Lim (2009) argues that students are aware of the quality problems of Wikipedia but 
confused about how to deal with them. This tension calls for pedagogical interventions that help students to scrutinize the problems of information evaluation.

Sundin (2011) made an ethnographic study of the everyday practices of Wikipedia editors and found that the construction of knowledge and referencing external sources are fairly transparent processes. He concludes that this makes Wikipedia an excellent forum to discuss and demonstrate the credibility of information. Jennings (2009) compared the Wikipedia guidelines with the information literacy standard of ACRL (2000) and found that they overlap quite a lot. Basically, Wikipedia offers a framework for IL instruction which adheres to the IL standards.

\section{Research questions}

The programmes of the courses investigated in the pilot study did not include a library visit. The teachers were shocked by the students' almost exclusive use of Web sources. In the courses designed for the main study, the teachers decided to add a library session to the course programme to activate the use of printed materials. Thus our first research question is:

RQ1. How does a library visit as one element of the course programme affect the students' choices of sources?

Students' low engagement in working with sources and producing text of their own (high rate of copy-pasting) and in properly acknowledging the sources (plagiarism) are well known problems in students' assignments. The research suggests that poor information literacy practices are related to failure to design meaningful and manageable assignments (e.g. Kuhlthau 2004; Limberg et al. 2008). We investigated the extent of low engagement in the source-based writing in two classes and differently designed assignments by asking:

RQ2. How much do articles composed in differently profiled assignments contain sentences

a. paraphrasing beyond copy-pasting? 

b. $\quad$ summarising within and synthesising across sources?
c. plagiarising sources?
d. building arguments credibly on sources?

Copy-pasting and plagiarism are associated with a tendency to use Web sources instead of printed sources. We aimed to ascertain if low engagement in the writing process was related to the types of sources used:

RQ3. Is the use of printed and Web sources similar or different in terms of
a. copy-pasting?
b. plagiarism?
c. summarising within and synthesizing across sources?
d. building arguments credibly on sources?

In addition, we collected reflections from the librarian and teachers on their roles in the project. These qualitative results are presented in the discussion section.

\section{Case courses}

We started with a pilot study on two eight-week courses in an upper secondary school in the spring term 2010. Four groups of students participated in an eight-week geography course and seven groups in an eight-week biology course. Each group wrote an article for Wikipedia as part of the course programme. The main study was conducted during spring term 2011 . Thirty students divided into ten groups completed a course in Finnish literature. Twenty-eight students divided into seven groups completed a course in Finnish history. The members were randomly assigned to the groups.

The original plan in the main study was that each group should write and upload an article into the Finnish edition of Wikipedia. However, the history teacher decided to use the school's wiki as the writing forum because she considered it more flexible in designing the assignment in extensive 
topics. On both courses the instructions to writers were designed to be as similar as possible to the Wikipedia conventions.

The groups of students selected topics for their articles from a list prepared by the teacher. In the literature course each group worked on one classic Finnish novel. The teacher checked in advance that Wikipedia did not contain a complete article on the novel. The students were required to read the novel first and write a personal literary essay on it before the group work on the source-based writing task started. In addition to the analysis of the novel itself, the students were required to write about the author and her/his works in general, about the reception of the novel in its day, and about the role of the author/work in Finnish literature.

On the history course, the teacher had prepared topics on Finnish history dealing with the period from the Civil War of 1918 to the beginning of the Winter War in 1939. The topics were quite extensive: The Civil War (1918), a dispute over the Finnish constitution (1918-19), economic development, the role of the left wing, the role of the right wing and foreign policy. The articles in the last four topics were intended to cover the period of 1918-39. For each topic, the teacher had listed sub-topics to help students to comprehend what themes the article should discuss.

In the literature class, the assignment was introduced during the second week of the course and the articles were completed in the sixth week. In the history class, the start was a week later and the end a week earlier than in the other class. The students of the literature class were given two weeks' extra time to read the novel and write the literary essay before approaching the source-based writing task.

The assignment was introduced, written guidelines were distributed, groups formed, and topics for the articles selected at the first session. The information specialist took part in the case courses, discussed the assignments with the teachers and taught the students how to make a proper wiki article and how to seek and process information for it. 
The second session was a visit to the nearby City Library. One 30- minute session was devoted to the library collections and services and another session to searching in the internet. The librarian was informed of the topics selected and had collected materials from the library collection for the students to look at. Time was also reserved for students to search in the library catalogue and directly browse in the collection. The teacher and the librarian gave the students hints and answered their questions. Most but not all students took part in the library visit.

After the visit to the library the students worked the next five (on the history course four) sessions in the computer classroom to search for information, to select and read sources found and to write texts for the articles under the teacher's supervision. On the history course, a substitute teacher was supervising the class in two sessions instead of the teacher in charge. We observed that the students worked less actively in the absence of their own teacher. Eventually many groups in the history class were badly behind schedule and completed their articles in panic. On the literature course, the class had one extra session allocated for working in the computer classroom, the teacher constantly reminded them of the deadlines, and students worked and collaborated more actively in their groups.

\section{Text transformation categories}

The comparison between the sources and the texts written was based on a framework of text transformation categories composed in the main study (Sormunen, Heinström, Romu \& Turunen 2012). The dimensions applied in this study are the following:

1. Degree of paraphrasing

2. Degree of synthesis

3. Credibility in building arguments on the basis of sources

4. Accuracy of citing 
The degree of paraphrasing indicates the extent to which the writer uses his/her own words in source-based writing (categories: copy-paste / near copy-paste / paraphrased / own text). The degree of synthesis measures the extent to which the writer connects pieces of information from different parts of a single source or from multiple sources (categories: sentence / paragraph / source /multiple sources /combined with own text). Credibility indicates how soundly the arguments evinced in a sentence rely on the evidence presented in the sources used (categories: credible / ambiguous / error / weak source). Accuracy of citing deals with the precision of linking the written sentence to the sources used (categories: sentence / paragraph / article /other / plagiarism / cheating).

For detailed category definitions, see Sormunen et al. (2012).

\section{Data collection}

We collected all the articles written and sources used in them (also non-cited when identifiable) applying a method developed in our earlier studies (Sormunen \& Lehtiö 2011; Sormunen et al. 2012). Two second-year Master's degree students were recruited as research assistants. One of them was studying Finnish literature and the other history.

All the articles were split into sentences and stored in MS-Word tables. For each sentence, the sources used were searched starting from the closest text citations and expanding to plagiarism tests in the Web. If a substantial share of article sentences still lacked identified sources (>10\%) we checked the textbooks available to students and the materials mentioned by students in the interviews.

Plagiarism checking was done mainly by Wikipedia and Google searches. To avoid problems of text variation caused by paraphrasing we selected up to four "best" words from each sentence as keyword candidates for Wikipedia searches. Queries were made by using all combinations of two keywords (maximum of six queries if necessary). A similar procedure was applied in the Google 
searches but a set of five keyword candidates was used first. The queries were made by using all keywords and combinations of four keywords (maximum five attempts). In each search result, a set of 20 first hits was checked.

Articles and sources were only a small part of the data collected from the process. We also interviewed groups of students and teachers, used questionnaires to collect personal responses, collected reports and self-assessments written by students, project memos written by the librarian and teachers etc. We use some of this data to complement the views in the discussion section.

\section{Data analysis}

The research assistants became familiar with the task by applying the codes to a set of two articles (one in literature and one in history). The codes and coding guidelines were revised on the basis of the problems encountered. Next, a consistency test was conducted by coding a new set of two articles. The overall consistency reached 91-95 per cent. After the consistency tests each research assistant coded the data of her/his course alone.

The coding data was first collected into Excel tables and after error-checks and pre-processing transferred into (the) SPSS software. All variables to be examined were categorical and thus the data were organized into contingency tables. The chi-square $\left(\chi^{2}\right)$ measure was used to test the statistical significance of differences in the distributions of column and row frequencies (see Siegel \& Castellan 1988, 123-124). We used $p<0.05$ as the critical level of statistical significance.

\section{Summary of articles and sources}

The summary of the characteristics of articles written by the student teams is presented in Table 1 . The average length of the articles was 100 sentences in the history and 66 in the literature articles, but the number of sentences per student was surprisingly similar: 25 sentences in the history and 23 sentences in the literature class. The volume of texts analysed in the set of literature articles was 
smaller because we excluded from the analysis sections based on the direct literary analysis of the novel (description of the plot and characters).

The fourth column of Table 1 reports in how many sentences the analyst was not able to identify the source of the sentence. The overall share of sentences where the search for sources failed was about six per cent for history articles and about ten per cent for literature articles. Thus the analysis covers about 90-94 per cent of the source-based text written by the students.

[Table 1 about here]

\section{Findings}

\section{RQ1: Does a library visit affect students' choice of sources?}

The numbers of printed and Web sources used in each article are presented in Table 1 (columns 513). The last column lists the numbers of sources cited but - according to our analysis - not used by the students.

The overall trend in the main study was that, on the average, the students of both courses used about four printed sources per article. Web sources were used less in the literature class (about three per article) than in the history class (about thirteen per article). In practice, all printed sources were books. In very few cases students had used their textbooks or printed reference sources. None cited printed journals or similar sources. The spectrum of Web sources used was much wider, including journal and newspaper articles, Master's theses and $\mathrm{PhD}$ dissertations, materials from theme-related academic or governmental Web sites. The use of Wikipedia and teaching materials was also quite common. Two literature groups and four history groups plagiarised Wikipedia extensively (three or more sentences).

The effect of the library visit on the use of printed sources seems obvious. In the pilot study we observed that very few of the sources (4\%) were printed (books). In the main study, the share of 
printed sources was about 59 per cent (3.0 out of 7.3 ) in the literature class and about 22 per cent (3.7 out of 16.6) in the history class. All groups used printed sources.

Table 1 also shows that in both groups about 23 per cent of the sources used were not included in the list of references (i.e. indications of plagiarism). Sometimes the plagiarism was accidental. For example, one student said in the last session when the articles were uploaded to the wiki that he was not aware of the strict deadline. He could not complete the list of references because all his materials were at home (!).

\section{RQ2: How did students transform information from the sources?}

The source-related characteristics of texts written by students in the history and literature classes are summarised in Table 2 (first three data columns).

Degree of paraphrasing. Overall, slightly more than half of sentences were written in paraphrased form and the share of copy-pasted text was nine per cent. Copy-pasting was equally common in both assignment groups (9\%) but paraphrasing was more typical in the literature assignments (65\%) than in the history assignments (49\%). The articles of the history class contained more mechanically edited text (42\% vs. $26 \%)$. The measured difference was statistically significant $(\chi 2(2)=23.5$; $\mathrm{p}=0.000)$.

Degree of synthesis. The results show that most sentences written (58\%) were derived from a single sentence in the source. About one third of sentences $(35 \%)$ summarised the content of a single source. Seven per cent of sentences synthesised contents from two or more sources. A small but statistically significant difference was observed between the groups $\left(\chi^{2}(2)=10.8 ; p=0.004\right)$. The students of the literature course showed a tendency to summarise and synthesise slightly more actively. 
Accuracy of citing. The overall result was that in 60 per cent of sentences the text citation was assigned to the sentence itself or the surrounding text paragraph. Further, in about a quarter of sentences (24\%) the source was in the list of references. In 16 per cent of sentences the source was plagiarised (cheating included). The history group was more meticulous in marking text citations $\left(\chi^{2}(2)=28.3 ; p=0.000\right)$. An interesting result was that plagiarism was equally common in both groups $(16 \%)$.

Credibility of arguments. The results show that the students constructed their arguments well on the sources. In 85 per cent of sentences, we could not find even minor problems in the students' way of interpreting the content of the sources. The difference measured between courses was not statistically significant.

[Table 2 about here]

\section{RQ3: Is information similarly transformed from printed and Web sources?}

The characteristics of texts written on the basis of printed and Web sources are presented in Table 2 (three last data columns). Twenty-nine sentences synthesising information from both printed and Web sources were excluded decreasing the basic dataset to 916 sentences.

Degree of paraphrasing. The figures reveal that direct copy-pasting was more common with Web sources (14\% vs. 5\%) and paraphrasing in using printed sources (57\% vs. 48\%). Mechanical transformations were equally common $(38 \%)$ in the use of both source types. The difference measured in copy-pasting and paraphrasing was statistically significant $\left(\chi^{2}(2)=21.8 ; p=0.000\right)$. This result suggests that students exploit the technical easiness of copying Web sources at the cost of paraphrasing.

Degree of synthesis. Information was summarised and synthesised similarly from printed and Web sources $(\chi 2(2)=0.125 ; p=0.939)$. 
Accuracy of citing. The results corroborate the widespread experience that plagiarism is associated with the use of Web sources. Twenty-nine per cent of sentences based on a Web source were products of plagiarism while this was only five 5 per cent in texts relying on a printed source $\left(\chi^{2}\right.$ $(2)=97.7 ; p=0.000)$. The most commonly plagiarised source was Wikipedia.

Credibility of arguments. No association was observed between source types and the credibility of arguments since the measured difference was not statistically significant $\left(\chi^{2}(1)=0.747 ; p=0.388\right)$.

\section{Discussion}

$R Q 1$. The findings strongly suggest that the special session organised in the City Library activated students to exploit printed sources, especially books. In the interviews, the students reported with satisfaction that the librarian had collected some books in advance about each topic of the assignment for the students. In the literature class, the books offered seemed to meet the students' needs. The students of the history class were less satisfied and claimed that the books offered did not directly meet their needs. The librarian commented that in her view the books were relevant to the students' topics but many students were obviously too impatient to work with books requiring substantial reading effort.

The higher satisfaction in the literature class with the books offered by the librarian and their active use may relate to the type of assignment. Each assignment was anchored to a well-known classic novel and the librarian could easily point out general and specific sources relevant for that task. The students of the history class had difficulties in finding a focus for their inquiry (cf. Kuhlthau 2004). Some of them were desperately searching for information in the Web very late in the process. This is typical of survival strategies, where students seek right answers from the sources rather than build their knowledge. (see Limberg, Alexandersson, Lantz-Andersson \& Folkesson 2008)

$R Q 2$. The answers to the second research question emphasise that students wrote and used sources differently in differently profiled assignments. In the literature class, the students were more active 
in paraphrasing and synthesising sources. The students of the history course cited more meticulously but were behind in all other areas of source-based writing. The building of arguments on sources was credible in both groups.

We can only draw some preliminary conclusions as to why the articles in the literature course were more advanced. The design of the literature assignment was more focused (the classic novel anchored the topic), the personal essay prepared the students for the task, the structure and content of the required end-product was specified more explicitly (a Wikipedia article of a particular type), and the progress of groups was controlled more intensively (check points, the students' "own" teacher present at all sessions). Earlier research suggests that keeping the contextual aspects of the assignment simple and fixed seems to help students to focus on the content of the assignment and to achieve better outcomes (see Limberg et al 2008; Hongisto \& Sormunen 2010).

$R Q 3$. The comparison of information transformed from printed and Web sources shows that 1) copy-pasting instead of paraphrasing and 2) plagiarism instead of acknowledging sources are more common in the use of Web sources. The findings corroborate the widely shared view that the Web has an obvious role in inappropriate practices of source-based writing (see e.g. McGregor \& Williamson 2005).

Reflections by the teachers. The teachers perceived that the case courses necessitated a great deal of extra work by the teacher. Compiling Wiki instructions and searching background information about the topics as well as course management caused several hours of extra work. According to the history teacher, the groups of students had problems in collaboration. Writing references and finding relevant sources was also difficult. The course schedule was too tight for the introduction of a new learning method: the students learned only little about the topics of the other groups. The teacher commented that she might use wiki again but only on a smaller scale assignment. 
The literature teacher also noted that much of the course went on studying a fairly narrow topic area. On the other hand, the students learned other skills such as literature analysis, source criticism, information search, collaborative work, project management and writing skills. The literature teacher would use Wikipedia assignments again, but only if the students were already familiar with Wikipedia practices.

Overall, the teachers considered that understanding the importance of IL skills has grown during the past few years in Finland. IL-skills are mentioned in the national curriculum as a goal in almost every subject. In practice the teaching of IL skills and the teaching staff's own IL skills vary a lot. Training in IL skills for teachers is often linked to ICT training, which has worked quite well. ICT offers the tools and IL offers access to content. At the time of this study the Tieto haltuun project had not yet fully started to offer training for teachers, but this has changed since the spring 2012. The continuing education for the teaching staff has been made the main focus in the project.

Teachers want their continuing education to be practical and useful for their own teaching. It would be ideal to train only teachers of a specific subject and school level at the same time. Simple examples and models of how to implement IL skills in teaching are very important in order to bring the teaching of IL skills into practice. It would be ideal, if the teachers were given tools to follow the stream of news and discussions on the rapid change of the field.

Reflections by the librarian. The librarian engaged on the project concluded that in order to design and deliver successful training librarians should know about the aim and the content of a particular course and the students' assignments. This makes it possible for the librarian to seek the best material and choose the most useful content for the lesson. In order to give the students what they really need and can comprehend, librarians should have a realistic conception of an average student's IL skills. 
The librarian needs to have education and experience in both information science and pedagogy. Since this is very rare, students of information sciences at university should have more opportunities for pedagogical studies. Librarians should also have a better understanding of an average student's IL skills and of everyday life in modern schools. It would be good to follow the discussion on education and schools. Close connections to schools is the key to developing successful collaboration between schools and libraries.

The librarian found she has a good opportunity to see the students seeking information, which gave her a better understanding of their IL skills. This experiment suggested that IL teaching in libraries works better when it is integrated into a course programme. This gives students an opportunity to start practising their IL skills immediately and also makes them more motivated listeners. The students on the Finnish literature course were more successful in finding relevant literature. They already had a good conception of the assignment when they came to the library, and were able to start seeking information more efficiently. In future it would be good to advise the teachers to prepare the class for the library course well enough.

Some aspects of the courses were found challenging both by the library and teaching staff. On the history course especially it was a little challenging to motivate the students to work for themselves. Some were eager to make the librarian do the searching for them. They had not thought out the assignment well enough to mount an efficient search. The assignments may also have been a little too challenging for them.

It also became obvious to the librarian that many students did not know how to efficiently seek information from a book. Especially seeking from various books and combining facts proved to be too difficult (or bothersome) for some. The librarian had instructed the students to use indices or tables of contents, but this proved to be too little too late. The students tended to use books as they use the internet, browsing superficially and quickly discarding a source they thought non-promising. 
This is something that needs to be addressed in greater detail on future courses, possibly starting with younger students.

\section{Conclusions}

The analysis of the Wikipedia and wiki articles written shows that a carefully planned library intervention can help to activate students to use printed materials in their source-based writing assignments. Our findings corroborate the generally held view that students tend to copy-paste and plagiarise, especially when exploiting Web sources. However, we do not conclude that students should be forced to use printed sources instead of Web sources. Rather, we see the problem in the poor design of source-based assignments. Established models for information literacy instruction to overcome the key problems are available (see Kuhlthau, Maniote \& Caspari 2004; Eisenberg 2008) but practising teachers do not apply them (see also Limberg et al. 2008).

The teachers felt that the learning objectives regarding subject contents were not met, but that the students probably learned other useful skills. Further, they commented that if the students' wiki skills were better, they would consider using the tools again. Although the teachers talked about the wiki the comments also apply to the situation of IL instruction in general. It is difficult to find space for learning good IL practices in the school tradition emphasising subject-specific knowledge. Teachers are always busy in meeting the content requirements of the curriculum in the various subjects. Self-directed learning with sources is always a slow process. Similarly, advanced IL practices cannot be adopted if student-centred work methods are not integrated into the curricula at different levels of education. How to find enough time for both learning IL practices and subject contents is a fundamental dilemma in schools.

\section{Acknowledgements}


The paper reports a joint study of the KnowId and "Tieto haltuun" projects. The authors thank the teachers of the case courses in the City of Tampere. We are also grateful to Leeni Lehtiö and Teemu Mikkonen, who took care of the data collection during the case courses.

\section{List of references}

- Achterman, D. (2005). Surviving Wikipedia - improving student search habits through information literacy and teacher collaboration. Knowledge Quest 33(5), 38-40.

- Eisenberg, M.B. (2008). Information literacy: essential skills for the information age. Journal of Library \& Information Technology 28(2), 39-47.

- Harouni, H. (2009). High school research and critical literacy: social studies with and despite Wikipedia. Harvard Educational Review 79(3), 473-494.

- Head, A. \& Eisenberg, M. (2010). How today's college students use Wikipedia for course related research. First Monday 15(3-1). Retrieved 12 July 2011 from http://firstmonday.org/htbin/cgiwrap/bin/ojs/index.php/fm/article/viewArticle/2830/2476.

- Hongisto, H. \& Sormunen, E. (2010). The challenges of the first research paper observing students and the teacher in the secondary school classroom. In: a. Lloyd \& S. Talja (Eds.) Practising Information Literacy: Bringing Theories of Learning, Practice and Information Literacy Together. Wagga Wagga: Centre for Information Studies, pp. 95120. Retrieved 11 January 2012 from https://www12.uta.fi/blogs/knowid/files/2010/05/Hongisto_Sormunen_PIL2010.pdf.

- Huvila, I. (2010). Where does the information come from? Information source use patterns in Wikipedia. Information Research 15(3), paper 433. Retrieved 12 July 2011 from http://InformationR.net/ir/15-3/paper433.html. 
- Jennings, E. (2009). Using Wikipedia to teach information literacy. College \& Undergraduate Libraries 15(4), 432 - 437. Retrieved 12 July 2011 from http://dx.doi.org/10.1080/10691310802554895.

- Julien, H. \& Baker, S. (2009). How high-school students find and evaluate scientific information: A basis for information literacy skills development. Library \& Information Science Research 31(1), 12-17.

- Kuhlthau, C.C. (2004). Seeking meaning: a process approach to library and information services. 2nd ed. Westport, Connecticut: Libraries Unlimited.

- Kuhlthau, C.C., Maniotes, L.K. \& Caspari, A.K. 2007. Guided inquiry. Learning in the 21th century. Westport: Libraries Unlimited.

- Limberg, L. (1999). Experiencing information seeking and learning. Information Research 5 (1) paper 68. Retrieved 12 January 2012 from http://informationr.net/ir/51/paper68.html.

- Limberg, L., Alexandersson, M., Lantz-Andersson, A. \& Folkesson, L. (2008). What matters? Shaping meaningful learning through teaching information literacy. Libri 58(2), $82-91$.

- Lim, S. (2009). How and why do college students use Wikipedia? Journal of the American Society for Information Science and Technology 60(11), 2189-2202.

- McGregor, J. \& Streitenberger, D. (2004). Do scribes learn? Copying and information use. In: M. K. Chelton and C. Cool (Eds.), Youth information-seeking behavior: theories, models and issues. Lanham: Scarecrow Press. 95-118.

- McGregor, J. \& K. Williamson. (2005). Appropriate use information at the secondary school level: Understanding and avoiding plagiarism. Library and Information Science Research 27(4): 496-512. 
- Siegel, S. \& Castellan, N.J. (1988). Nonparametric statistics for the behavioral sciences. New York: McGrawHill.

- Sormunen, E. \& Lehtiö, L. (2011). "Authoring Wikipedia articles as an information literacy assignment - copy-pasting or expressing new understanding in one's own words?" Information Research 16(4) paper 503. [Available at http://InformationR.net/ir/16-4/paper503.html].

- Sormunen, E., Heinström, J., Romu, L. \& Turunen, R. (2012). A method for the analysis of information use in source-based writing. Paper accepted to ISIC 2012 conference, Tokyo, Japan, Sept 4-7, 2012. 23 pages.

- Sundin, O. (2011). Janitors of knowledge: constructing knowledge in the everyday life of Wikipedia editors. Journal of Documentation 67(5): 840 - 862. 
Table 1. Summary of articles and sources used.

\begin{tabular}{|c|c|c|c|c|c|c|c|c|c|c|c|c|c|}
\hline \multirow[b]{2}{*}{ Team\# } & \multicolumn{3}{|c|}{ Sentences } & \multicolumn{3}{|c|}{ Cited\&used sources } & \multicolumn{3}{|c|}{ Plagiarised sources } & \multicolumn{3}{|c|}{ All sources used } & \multirow{2}{*}{$\begin{array}{c}\text { Cited } \\
\text { sources } \\
\text { not used }\end{array}$} \\
\hline & Written & Analysed & $\begin{array}{c}\text { Source } \\
\text { unknown }\end{array}$ & Web & Printed & Subtotal & Web & Printed & Subtotal & Web & Printed & Total & \\
\hline \multicolumn{14}{|c|}{ History course } \\
\hline $\mathrm{H} 1$ & 116 & 116 & 8 & 11 & 4 & 15 & 4 & 1 & 5 & 15 & 5 & 20 & 1 \\
\hline $\mathrm{H} 2$ & 125 & 125 & 11 & 10 & 4 & 14 & 1 & 0 & 1 & 11 & 4 & 15 & 0 \\
\hline $\mathrm{H} 3$ & 68 & 68 & 3 & 12 & 3 & 15 & 10 & 0 & 10 & 22 & 3 & 25 & 0 \\
\hline $\mathrm{H} 4$ & 74 & 74 & 2 & 7 & 1 & 8 & 1 & 0 & 1 & 8 & 1 & 9 & 0 \\
\hline $\mathrm{H} 5$ & 143 & 143 & 12 & 12 & 4 & 16 & 3 & 1 & 4 & 15 & 5 & 20 & 0 \\
\hline $\mathrm{H} 6$ & 59 & 59 & 1 & 5 & 1 & 6 & 3 & 1 & 4 & 8 & 2 & 10 & 11 \\
\hline $\mathrm{H7}$ & 116 & 116 & 6 & 10 & 5 & 15 & 1 & 1 & 2 & 11 & 6 & 17 & 2 \\
\hline Sum & 701 & 701 & 43 & 67 & 22 & 89 & 23 & 4 & 27 & 90 & 26 & 116 & 14 \\
\hline Average & 100,1 & 100,1 & 6,1 & 9,6 & 3,1 & 12,7 & 3,3 & 0,6 & 3,9 & 12,9 & 3,7 & 16,6 & 2,0 \\
\hline STDev & 32,6 & 32,6 & 4,4 & 2,6 & 1,6 & 4,0 & 3,2 & 0,5 & 3,1 & 4,9 & 1,8 & 5,7 & 4,0 \\
\hline \multicolumn{14}{|c|}{ Literature course } \\
\hline $\mathrm{L} 1$ & 87 & 46 & 0 & 6 & 3 & 9 & 0 & 0 & 0 & 6 & 3 & 9 & 2 \\
\hline $\mathrm{L2}$ & 55 & 17 & 1 & 0 & 4 & 4 & 1 & 1 & 2 & 1 & 5 & 6 & 0 \\
\hline $\mathrm{L3}$ & 36 & 18 & 1 & 1 & 3 & 4 & 0 & 0 & 0 & 1 & 3 & 4 & 0 \\
\hline $\mathrm{L4}$ & 107 & 69 & 17 & 0 & 6 & 6 & 2 & 1 & 3 & 2 & 7 & 9 & 0 \\
\hline $\mathrm{LS}$ & 77 & 36 & 0 & 4 & 6 & 10 & 1 & 0 & 1 & 5 & 6 & 11 & 1 \\
\hline $\mathrm{L6} 6$ & 88 & 41 & 9 & 0 & 5 & 5 & 0 & 0 & 0 & 0 & 5 & 5 & 0 \\
\hline 17 & 83 & 48 & 5 & 0 & 4 & 4 & 2 & 0 & 2 & 2 & 4 & 6 & 1 \\
\hline$\llcorner 8$ & 52 & 30 & 0 & 2 & 4 & 6 & 6 & 1 & 7 & 8 & 5 & 13 & 0 \\
\hline L9 & 38 & 23 & 3 & 0 & 3 & 3 & 0 & 0 & 0 & 0 & 3 & 3 & 0 \\
\hline $\mathrm{L} 10$ & 37 & 24 & 1 & 3 & 2 & 5 & 2 & 0 & 2 & 5 & 2 & 7 & 2 \\
\hline Sum & 660 & 352 & 37 & 16 & 40 & 56 & 14 & 3 & 17 & 30 & 43 & 73 & 6 \\
\hline Average & 66,0 & 35,2 & 3,7 & 1,6 & 4,0 & 5,6 & 1,4 & 0,3 & 1,7 & 3,0 & 4,3 & 7,3 & 0,6 \\
\hline STDev & 25,5 & 16,3 & 5,5 & 2,1 & 1,3 & 2,3 & 1,8 & 0,5 & 2,2 & 2,8 & 1,6 & 3,2 & 0,8 \\
\hline
\end{tabular}


Table 2. Characteristics of sentences in articles written by students in a source-based writing assignment.

\begin{tabular}{|c|c|c|c|c|c|c|c|}
\hline \multirow{2}{*}{\multicolumn{2}{|c|}{$\begin{array}{l}\text { The aspect of source-based } \\
\text { writing }\end{array}$}} & \multicolumn{2}{|c|}{ Class } & \multirow[b]{2}{*}{$\begin{array}{c}\text { Total } \\
(n=945)\end{array}$} & \multicolumn{2}{|c|}{ Source type } & \multirow[b]{2}{*}{$\begin{array}{c}\text { Total } \\
(n=916)\end{array}$} \\
\hline & & $\begin{array}{c}\text { History }(n= \\
653)\end{array}$ & $\begin{array}{l}\text { Literature } \\
(n=292)\end{array}$ & & $\begin{array}{l}\text { Printed } \\
\text { sources } \\
(n=486)\end{array}$ & $\begin{array}{c}\text { Web } \\
\text { sources } \\
(n=430)\end{array}$ & \\
\hline \multirow{3}{*}{$\begin{array}{l}\text { Degree of } \\
\text { paraphrasing }\end{array}$} & copy-paste & $9 \%$ & $9 \%$ & $9 \%$ & $5 \%$ & $14 \%$ & $9 \%$ \\
\hline & near copy-paste & $42 \%$ & $26 \%$ & $37 \%$ & $38 \%$ & $38 \%$ & $38 \%$ \\
\hline & paraphrased & $49 \%$ & $65 \%$ & $54 \%$ & $57 \%$ & $48 \%$ & $53 \%$ \\
\hline \multirow{2}{*}{\multicolumn{2}{|c|}{ Total }} & $100 \%$ & $100 \%$ & $100 \%$ & $100 \%$ & $100 \%$ & $100 \%$ \\
\hline & & \multicolumn{3}{|c|}{$X 2(2)=23.5 ; p=0.000$} & \multicolumn{3}{|c|}{$\chi 2(2)=21.8 ; p=0.000$} \\
\hline \multirow{3}{*}{$\begin{array}{l}\text { Degree of } \\
\text { synthesis }\end{array}$} & sen-sen & $61 \%$ & $53 \%$ & $58 \%$ & $60 \%$ & $60 \%$ & $60 \%$ \\
\hline & summary & $34 \%$ & $37 \%$ & $35 \%$ & $36 \%$ & $37 \%$ & $36 \%$ \\
\hline & synthesis & $5 \%$ & $10 \%$ & $7 \%$ & $4 \%$ & $3 \%$ & $4 \%$ \\
\hline \multirow{2}{*}{\multicolumn{2}{|c|}{ Total }} & $100,0 \%$ & $100,0 \%$ & $100,0 \%$ & $100 \%$ & $100 \%$ & $100 \%$ \\
\hline & & \multicolumn{3}{|c|}{$x^{2}(2)=10.8 ; p=0.004$} & \multicolumn{3}{|c|}{$x^{2}(2)=0.125 ; p=0.939$} \\
\hline \multirow{3}{*}{$\begin{array}{l}\text { Accuracy of } \\
\text { citing }\end{array}$} & close & $65 \%$ & $49 \%$ & $60 \%$ & $67 \%$ & $51 \%$ & $60 \%$ \\
\hline & loose & $19 \%$ & $34 \%$ & $24 \%$ & $28 \%$ & $20 \%$ & $24 \%$ \\
\hline & missing & $16 \%$ & $16 \%$ & $16 \%$ & $5 \%$ & $29 \%$ & $16 \%$ \\
\hline \multirow{2}{*}{\multicolumn{2}{|c|}{ Total }} & $100 \%$ & $100 \%$ & $100 \%$ & $100 \%$ & $100 \%$ & $100 \%$ \\
\hline & & \multicolumn{3}{|c|}{$x^{2}(2)=28.3 ; p=0.000$} & \multicolumn{3}{|c|}{$x^{2}(2)=97.7 ; p=0.000$} \\
\hline \multirow{2}{*}{$\begin{array}{l}\text { Credibility of } \\
\text { arguments }\end{array}$} & no problem & $87 \%$ & $82 \%$ & $85 \%$ & $86 \%$ & $84 \%$ & $85 \%$ \\
\hline & problem & $13 \%$ & $18 \%$ & $15 \%$ & $14 \%$ & $16 \%$ & $15 \%$ \\
\hline \multirow[t]{2}{*}{ Total } & & $100 \%$ & $100 \%$ & $100 \%$ & $100 \%$ & $100 \%$ & $100 \%$ \\
\hline & & \multicolumn{3}{|c|}{$X^{2}(1)=3.2 ; p=0.072$} & \multicolumn{3}{|c|}{$\chi^{2}(1)=0.747 ; p=0.388$} \\
\hline
\end{tabular}

